\title{
ARBITRAJE INTERNACIONAL Y TOMA DE MEDIDAS CAUTELARES
}

\section{ARBITRAGEM INTERNACIONAL E TOMA DE MEDIDAS CAUTELARES}

\section{Liliana Etel Rapallini**}

Resumen: Sin lugar a dudas, la evolución del arbitraje de Derecho Privado Comercial Internacional tanto como Regional ha evidenciado progresos técnicos como jurídicos. Sólo basta con reparar en la influencia cada vez más notoria de la "lex mercatoria", en el avance en el uso de la video conferencia y otros medios de comunicación virtual, hasta llegar hoy día a la instalación progresiva del arbitraje "on-line". Pese a ello, y a la difusión del procedimiento arbitral, el mismo coexiste con áreas aún discutidas que operan como un velo u obstáculo sobre su celeridad y eficacia.Las áreas que adolecen son conocidas y una de ellas responde a la toma de medidas cautelares sin recurrencia a la justicia estadual. Pese a tratarse de una medida de cooperación jurídica, escaso ha sido el avance en las fuentes normativas.

Resumo: A evolução da arbitragem de direito privado comercial internacional e regional evidenciou, sem dúvida, progressos técnicos e jurídicos. Basta, para tanto, a observação da influência cada vez mais notória da "lex mercatoria", do avanço do uso da videoconferência e de outros meios de comunicação virtual e até da instalação progressiva nos dias de hoje da arbitragem "on-line". Apesar disso e da popularização do procedimento arbitral, o mesmo coexiste com áreas ainda discutíveis que operam como um véu ou obstáculo à celeridade e à eficácia. As áreas mais afetadas são conhecidas e uma delas seria a adoção de medidas cautelares sem a participação dos tribunais estatais. Apesar de se tratar de questão de cooperação jurídica, escasso tem sido o avanço das fontes normativas.

Palabras clave: Arbitraje internacional, Cautelar Palavras-chave: Arbitragem internacional, Cautelar

* Parte del artículo fue publicado en la Revista del Colegio de Abogados de La Plata, Año LIII No 73. ** Docente de grado y de posgrado especializada en Derecho Internacional Privado. Investigadora estable de la Facultad de Ciencias Jurídicas y Sociales de la Universidad Nacional de La Plata. Investigadora Invitada de la Real Academia de Jurisprudencia y Legislación de España. Directora del Instituto de Derecho Internacional Privado del Colegio de Abogados de La Plata. 


\section{ASPECTOS PRELIMINARES}

El arbitraje de derecho privado internacional difundido sobre todo en el área del Derecho Mercantil, tiene tras de sí razones justificativas muy estimables que aconsejan su conservación, difusión e incorporación como práctica.

Su evolución se sujeta a la coyuntura histórica y su uso, constituye una huída o escape de las instituciones jurisdiccionales del Estado procurando valores tales como efectividad, reducción de costos y de tiempo, inmediatez. No obstante se revalorizan principios tales como independencia e imparcialidad de los árbitros y buena fe procesal.

Razones como las evocadas han provocado conclusiones tales como considerar que las vías del derecho estricto no siempre resuelven los conflictos de los particulares, reconsiderando a la equidad como una balanza de equilibrio un tanto olvidada y tan incorporada a la esencia humana ${ }^{1}$.

Mercantil o comercial, poco interesa precisar aquello que se entiende lo suficiente, la realidad es que esa idoneidad de dicha materia para el arbitraje o de éste para aquella, se percibe en la vinculación generalizada de instituciones arbitrales a instituciones destinadas al comercio, tal el caso de las Cámaras de Comercio, desde los diferentes ámbitos nacionales hasta alcanzar el nivel internacional como se refleja en la CCI (Cámara de Comercio Internacional) ${ }^{2}$.

Nutridos instrumentos internacionales forjaron la solidez del arbitraje como medio alternativo de resolución de conflictos. La realización inicial en este orden la encontramos en el Protocolo de Ginebra del año 1925 destinado al compromiso arbitral y en su sucesor, el Convenio de Ginebra de 1927 sobre ejecución de laudos.

Sin duda alguna, el arbitraje tiene una importancia capital como medio para resolver las diferencias surgidas en las relaciones comerciales internacionales ${ }^{3}$; pero su espacio de destino propende a la expansión de su objeto.

Se habla de "derechos disponibles" idea eje de materia susceptible de llevar a arbitraje y que gira en torno de la categoría derechos personales de contenido patrimonial; a ello debemos sumarle la cuestión de "cesión o transferencia" aludiendo así a la voluntad del Estado de ceder o transferir, precisamente, determinada materia del derecho al procedimiento arbitral. Y es entonces cuando se observa su uso en

1 PRIETO CASTRO Leonardo (1955) "Problemas debatidos en el Primer Congreso IberoAmericano de Derecho Procesal y en particular, el arbitraje. Lecciones pronunciadas en la Universidad de Deusto los días 5, 6, y 7 de Diciembre de 1955”. Bilbao: ARTE.

2 OLIVENCIA RUIZ Manuel (2005) Arbitraje Mercantil-Ensayo sobre una justicia alternativa. Escritos Jurídicos. Sevilla: Fundación El Monte, p. 373.

3 BROTONS Antonio Remiro (1980) Sentencias arbitrales extranjeras. Madrid: Editoras de Derecho Reunidas. Madrid, p. 5. 
relaciones de consumo o en materia testamentaria.

Pese a sus bondades y a su difusión, el procedimiento de arbitraje no se autoabastece; existen ámbitos de coordinación entre los órganos jurisdiccionales estatales y las funciones de los árbitros.

Puede observarse, que antes del procedimiento de arbitraje los jueces están facultados para formalizar el nombramiento de árbitros. Instaurando el procedimiento de arbitraje, los árbitros pueden decidir la toma de medidas cautelares sin embargo, para darles efectividad han de requerir de las potestades coactivas de los jueces.

En la fase post arbitral la intervención judicial será ineludible en recursos de revisión, nulidad, reconocimiento y ejecución del laudo arbitral $^{4}$. En el último aspecto, la decisión emanada de un procedimiento de arbitraje suele ser cumplida voluntariamente; pero de ser precisa una ejecución forzosa habrá que recurrir a la organización judicial del Estado de origen o bien, a la de un Estado extranjero en virtud de los mecanismos de la cooperación jurídica internacional.

La realidad expone la convivencia del juez con el árbitro en determinadas instancias procesales.

Llegamos al corazón de la presente entrega, pues de lo hasta ahora reseñado se desprende un problema de naturaleza teórica que se traslada a la práctica pues convengamos que durante el desarrollo de las etapas del proceso de arbitraje es natural que el árbitro acceda a la toma de medidas cautelares.

Eclosiona entonces la disputa, de si el árbitro como conductor del proceso cuenta con efectiva posibilidad de hacer cumplir por el órgano administrativo correspondiente la toma de la medida cautelar ordenada sin que sea necesario el traslado hacia la justicia estatal.

Vale decir, que lejos estamos de contar con un criterio uniforme arrojando a la visión de la realidad, un resultado contradictorio desde todo punto de vista sobresaliendo la dicotomía que expone, que si a través del arbitraje recurrimos a una vía expedita derivando ésta puntuales etapas al sistema jurisdiccional tradicional, regresamos al espacio de donde pretendimos escapar.

Pareciera ser que subsisten constantes históricas pues el protagonista del tráfico mercantil -desde antiguo el mercader, pasando por el comerciante y en nuestros días el empresario- siempre ha recurrido a alternativas frente a la justicia ordinaria a fin de resolver los conflictos específicos. Aún más pues esa alternativa no sólo apunta al órgano encargado de administrar justicia -iurisdictio-, sino al proceso -iudicium- a través del cual se tramita el litigio ${ }^{5}$.

4 ESPUGLES MOTA Carlos (1997) "El juez y el árbitro en el Arbitraje Comercial Internacional”. Cuadernos de Derecho Judicial (1), p. 15-23.

5 OLIVENCIA RUIZ Manuel (2010) Derecho mercantil y proceso. Madrid: Estudios de la Real Academia de Jurisprudencia y Legislación, p. 196. 


\section{SUFICIENCIA DEL ARBITRAJE: TOMA DE MEDIDAS CAUTELARES}

Puntualmente, la adopción de medidas cautelares en el arbitraje bien sea interno o doméstico o bien internacional, es un tópico que entra en el plexo de atribuciones comprendidas en el marco de legalidad que deben asumir los árbitros ${ }^{6}$.

Ahora bien, convengamos en que el punto de partida y piedra basal del arbitraje está conformado por la cláusula o convenio arbitral.

Así por ejemplo, el art. 7.1 de la ley modelo de UNCITRAL sobre Arbitraje Comercial Internacional inspiradora de los arbitrajes internos como internacionales, define al convenio arbitral como aquel acuerdo de voluntades por el que las partes contratantes deciden someter a arbitraje todas o ciertas y determinadas controversias surgidas o que puedan surgir entre ellas respecto de una relación jurídica sea ésta contractual o no. Puede corresponder que se formalice por escrito e incluso con intervención notarial, tema hoy superado por la práctica de las transacciones a través de medios electrónicos ${ }^{7}$. Al decir de Santos Belandro lo importante es la existencia de cualquier medio de comunicación que deje constancia documental de la voluntad de ambas partes de someterse al arbitraje ${ }^{8}$. Desde ya, que los aciertos o desaciertos de su redacción redundan en la solvencia del proceso de arbitraje ante la eventualidad de llevarse a cabo; sustancialmente, ésta convención debe respetar la paridad entre partes de manera que la voluntad de someterse a arbitraje es un punto relevante para medir su posterior eficacia9.

Actualmente, un "convenio arbitral adhesivo"10 es el que está contenido en un contrato de adhesión en cuyo caso la validez de dicho convenio y su interpretación, se regirán por las normas aplicables al tipo de contrato del que se trate; ésta peculiaridad es frecuente en las relaciones de consumo donde la oferta pública y abierta de sumisión al procedimiento de arbitraje en caso de controversias emergentes de la contratación, es aceptada por el consumidor. La adhesión a pautas prefijadas resta una importante porción de voluntariedad, requerida para la eficacia de una expresa voluntad de ambas partes de un contrato

6 LORCA NAVARRTE Antonio María (2007) "Problemas prácticos y teóricos que plantea la adopción de medidas cautelares en el modelo de arbitraje UNCITRAL/CNUDMI”. Diario La Ley (6634), Madrid, 22 de enero de 2007.

7 El Proyecto de Código Civil y Comercial en estudio en la República Argentina enfatiza como requisito formal del acuerdo de arbitraje, la modalidad "por escrito".

8 SANTOS BELANDRO Rubén (2004) “¿Hasta qué punto puede diluirse la formalidad del Acuerdo de Arbitraje Internacional en América Latina". Revista Mexicana de Derecho Internacional Privado y Comparado, (15), p. 85

9 La propia "lex mercatoria" impone el ejercicio de la autonomía de la voluntad como condición de sometimiento a la vía arbitral.

10 ROGEL VIDE Carlos (2006) "El convenio arbitral y el arbitraje testamentario". Revista General de Legislación y Jurisprudencia, (3), p. 467. 
que se presume paritario y por la que se decide alejarse de la justicia ortodoxa y comprenderse en el procedimiento de arbitraje.

Empero, con mayor o menor creatividad de las partes, si el convenio arbitral propuesto recibe respuesta afirmativa la opción redunda en desestimar una vía, la justicia estatal, y sumirse a una alternativa también procesal, la del arbitraje ${ }^{11}$.

Siendo entonces, el arbitraje originado por un acuerdo de voluntades con amplio o restringido consenso activo, la posibilidad de incorporarse a un testamento un convenio arbitral no deja de resultar curioso y contrario a la regla general; pese a ello, ordenamientos como el español han incorporado el arbitraje testamentario ${ }^{12}$.

No obstante, el convenio arbitral más que un contrato de índole procesal es la expresión autónoma, abstraída de dependencia, de la inequívoca y fehaciente voluntad de las partes de otorgar determinada estructura al negocio jurídico en cuestión al que se destine.

El compromiso arbitral supone adopción de un sistema procesal; llegado el momento de interponer la reclamación, la parte actora pretende asegurar su prerrogativa.

Ahora bien, en el derecho comparado pueden admitirse varios sistemas en orden a la adopción de medidas cautelares. El que podríamos denominar tradicional, reconoce sólo la potestad judicial para hacer efectivas las medidas admitidas y ordenadas por el árbitro. El sistema moderno o amplio, toma un rumbo extremo y reconoce únicamente la potestad arbitral para la admisibilidad y toma de la medida requerida. El tercero, mixto o de convergencia, sienta un principio de alternatividad donde el peticionante opta entre una u otra vía criterio éste, incorporado al Acuerdo de Arbitraje para el Mercado Común del Sur por cierto innovador. Es notable que el sistema mercosureño además de innovador, tenga como finalidad fortalecer de un modo indudable la eficacia del arbitraje. Es más, desde la óptica cooperativa el acuerdo abre la puerta a la posibilidad de ser el mismo tribunal arbitral el que peticione a un juez extranjero la adopción de una medida cautelar sólo que éstas facultades deben estar expresamente avaladas por los Estados partícipes ${ }^{13}$.

Pero lo cierto es que los árbitros y el justiciable frente al considerable margen de duda, han de acudir inexorablemente al activismo judicial por cuanto goza de universal acatamiento la regla que indica que los árbitros carecen de potestad ejecutiva en cuanto a la efectiva traba de

11 "La procedencia de la jurisdicción arbitral se encuentra sujeta a la voluntad de los interesados quienes, mediante una cláusula compromisoria, pueden renunciar a la jurisdicción de los tribunales ordinarios y someterse a la primera". Extractado del fallo de la CNCom., Sala E, 20-03-2013, Omni security S.A. c. ADT Security Services S.A. s. Queja.

12 ALBALADEJO Manuel (1990) "El arbitraje testamentario". Actualidad Civil Aranzadi (6).

13 SANTOS BELANDRO Rubén (2008) Derecho Comercial Internacional. Montevideo: Asociación de Escribanos del Uruguay. Montevideo, p. 542. 
una medida cautelar ${ }^{14}$. En tanto, y alejando por un instante nuestra mirada de la finalidad de aseguramiento que venimos describiendo, también es posible afirmar que las medidas cautelares intentan evitar la autotutela ${ }^{15}$ conservando o innovando en la situación fáctica o jurídica existente al momento de editarse el conflicto. A menudo el proceso debe ofrecer una solución eficaz aunque provisoria, a fin de que las partes no se vean tentadas de hacer justicia por propia mano ${ }^{16}$.

Aflora una suerte de conclusión y es que el árbitro bajo éstas expectativas, queda sometido a una suerte de revisión jurisdiccional de sus decisorios relativos al tópico en cuestión.

Se ha pretendido más todavía. Valiéndose de instrumentos como la Ley Modelo UNCITRAL/CNUDMI se habla de la prosperidad de una medida cautelar "ex parte" o "in audita parte" lo que equivale a trabar la cautelar sin previa notificación al demandado. Y aquí debemos detenernos y meditar que el arbitraje pretende un procedimiento participativo en donde, por ejemplo, la rebeldía está erradicada. Visto así, el principio del debido proceso y el de bilateralidad están cumplidos. Es el árbitro quien debe velar por ellos de modo tal que la coherencia indica, que sólo por razones de urgencia debidamente probadas puede prosperar la traba de una medida cautelar sin encontrarse anoticiado el demandado ${ }^{17}$.

Éste último extremo podría profundizarse en el marco de la hipótesis y suponiendo que no se admita evadir la vía jurisdiccional estatal para la traba de la medida cautelar, cabe preguntarse si realmente tendrá fuerza ejecutoria la medida cautelar ordenada "ex parte" por decisorio de un árbitro, como un valor agregado al límite de sus facultades. Sobre el punto, en la Unión Europea la jurisprudencia elaboró un criterio unánime expresando, por ejemplo, que "Las resoluciones judiciales por las que se adoptan medidas provisionales y cautelares, dictadas sin que la parte contra la que vayan dirigidas haya sido citada para comparecer y destinadas a ejecutarse sin haber sido previamente notificadas a esta última parte, no pueden acogerse al régimen de reconocimiento y de

14 En verdad, el tema reconoce una raíz superior e intrincada cómo es el de precisar el concepto de jurisdicción y de allí en más saber si la actividad arbitral es jurisdiccional o no.

15 Sobre el punto, ver CAMPS Carlos Enrique (2012) Tratado de las Medidas Cautelares, tomo I. Buenos Aires: Abeledo Perrot, p. 214 y ss.

16 "El Estado al asumir la función de administrar justicia prohíbe a los individuos la autodefensa de sus derechos, y por tanto, no puede desentenderse de las consecuencias de la demora que necesariamente ocasiona la instrucción del proceso, de allí entonces que coloca en manos de los jueces y los litigantes los elementos procesales para evitar los efectos nefastos del transcurso del tiempo en el derecho de las partes, para lo cual instituye las llamadas medidas precautorias o cautelares, tales como el embargo, con el fin de preservar la eventual ejecución futura del deudor, limitando las facultades de disponibilidad o goce de los bienes." CC0102 MP 102864 RSI-944-97 I 7-8-1997.

17 ALBACAR LÓPEZ José Luis (1991) “El derecho a la tutela jurisdiccional”. La Ley (2), p. 914 y sgtes. 
Arbitraje internacional y toma de medidas cautelares. Liliana Etel Rapallini

ejecución...."18. De más está decir, que el criterio se extendió a los laudos arbitrales dado que como es universalmente aceptado ambos decisorios, sentencias y laudos, merecen idéntico tratamiento.

Cabe recapacitar que el principio de equiparación entre justicia estatal y justicia arbitral no debe extenderse al punto de revestir total identidad pues de ser así, la opción entre una y otra justicia carecería de sentido alguno.

Lo cierto es que la carencia de "imperium" en el árbitro para dar plena ejecución a una medida coactiva por naturaleza, no implica la ausencia de facultad para dictar la medida cautelar en sí misma pues éstas son cuestión incita de todo proceso ${ }^{19}$.

La decisión y la ejecución son instancias claramente diferenciadas, por una se resuelve la conveniencia y admisibilidad y por otra se lleva a la práctica ${ }^{20}$.

Analizando un único sector, siempre se cae en parcialidad. La toma de medidas cautelares moviliza a la autoridad jurisdiccional y a la administrativa encargada de cumplir la manda; si al margen de ser el objeto del arbitraje un caso interno o uno internacional, le adosamos que los bienes sobre los que reposarán las cautelares se encuentran en un Estado diferente al del Tribunal Arbitral, el esquema podrá aparecer como de mayor complejidad pero en verdad el interrogante es siempre el mismo: el decisorio arbitral es suficiente o se requiere de la participación de la justicia ordinaria y a su vez, el ordenamiento del Estado de origen y el del Estado rogado conciben en idéntico tenor las facultades y limitaciones de los árbitros. Obviamente, éstas apreciaciones adquieren mayor relieve si la medida cautelar se pretende peticionar y trabar con carácter previo a la instauración del proceso de arbitraje en sí mismo.

Como es fácil deducir, las bondades del arbitraje empalidecen por carencia de uniformidad de criterio. Pese a ello, el arbitraje avanza de manera ascendente y dinámica en el mundo comercial e incluso en el área de inversiones. La razón obedece a constantes tales como especialidad, neutralidad, flexibilidad, celeridad, confianza, privacidad y simplicidad empero, es principio universalmente acatado que los órganos judiciales competentes son los únicos habidos para conocer del exequátur de laudos arbitrales extranjeros ${ }^{21}$.

18 STJCE 21 de mayo 1980, Denilauler vs. Couchet Frères (Recueil, 1980, páginas 1553-1584). $19 \mathrm{El}$ árbitro tiene reconocida decisión pero no tiene imperio vale decir, decide pero no ejecuta. 20 MARCHESINI Gualterio Martín (2006) "Las medidas cautelares en el proceso arbitral comercial". La Ley, 2006-C, Buenos Aires, mayo 26.

21 GÓMEZ JENE Miguel (2004) "El arbitraje internacional en la nueva ley de arbitraje". Diario La Ley (5952), Madrid, febrero 11. 


\section{CONCLUSIONES: RESPUESTAS ACTUALES DEL ARBITRAJE INTERNACIONAL}

El arbitraje de Derecho Privado Internacional se canaliza en coordenadas diferentes de las del interno pese a que las dos variables comparten idénticas insuficiencias o adolescencias. La peculiaridad de la especie internacional radica en las relaciones jurídicas que lo ocupan, dado que éstas no se encuentran vinculadas a un único ordenamiento jurídico al punto de ser necesario desmenuzarlas, a fin de determinar cuál o cuáles de sus elementos surgen como preferentes al resto para el correcto encuadre y determinación del grado de internacionalidad.

Se señala como Derecho del Arbitraje Internacional, al conjunto de normas establecidas como consecuencia de la caracterización internacional del arbitraje en función de los elementos que en él concurren y del objeto sobre el que versa.

Cobra realidad el "estatuto jurídico del arbitraje" como un acervo jurídico especial ${ }^{22}$. Sus normas se originan en diversas fuentes en razón de los distintos círculos normativos que intervienen en el diseño de la operación arbitral internacional en su conjunto.

Actualmente, el arbitraje sobre todo internacional, se orienta hacia la obtención de resultados optimizando su rendimiento. A la mentada y reforzada idea de estructurarse con un régimen especial y con la unificación a través de la codificación, se anexa su afianzamiento jurisdiccional. En avance, desde el momento en que el arbitraje se institucionaliza como modo habitual de solución de controversias, la pretensión es reforzar la función de los árbitros que conduce a la autonomía del procedimiento y de sus actores; autonomía que se refleja en notoria expansión de la jurisdicción arbitral y su desvinculación de la jurisdicción estatal, permaneciendo en manos de ésta última lo atinente a ejecución del laudo arbitral.

Cabe concluir, que la prevención frente al arbitraje e incluso su rechazo frente al monopolio jurisdiccional del Estado, ha dado progresivo paso al reconocimiento del arbitraje como un instrumento adecuado para prevenir y reducir la sobrecarga de trabajo de los tribunales y por ello merecedor de ventajas o incentivos y finalmente, a generar convicción generalizada sobre la conveniencia de promover la difusión del arbitraje, mediante la instrumentación normativa del principio del "favor arbitri" 23.

A ello, debemos añadir que la voluntad expresa y fehaciente de las partes conforma el indicador de sumisión a una jurisdicción

22 MERINO MERCHÁN José Francisco, CHILLÓN MEDINA José María (2006) Tratado de Derecho Arbitral. 3ra. ed. Madrid: Thomson - Civitas, p. 821, 863, 870.

23 VERDERA Y TULLES Evelio (2005) La ley 60/2003, de arbitraje entre la tradición y la innovación. Madrid: Real Academia de Jurisprudencia y Legislación, p. 92 y siguiente. 
especial como es la arbitral y en cuestiones o materias delegadas por el mismo poder estatal; en consecuencia, las medidas cautelares forman parte del proceso principal sobre el cual los árbitros tienen potestad de conocimiento y de resolución ${ }^{24}$. Al respecto, la doctrina no se ha silenciado y es así como se invita a un cambio cultural frente al arbitraje en procura de un mejoramiento del mejoramiento normativo ${ }^{25}$. Por otra parte, la existencia de un convenio arbitral expone duplicidad de efectos; el positivo señala que por él las partes se obligan a cumplir con lo allí estipulado; el negativo resuelve el entuerto, pues su existencia impide a los órganos jurisdiccionales estatales conocer de las controversias sometidas a arbitraje $\mathrm{e}^{26}$.

Mientras tanto, cabe esperar un estatuto universal de manera que las decisiones de los árbitros fueran reconocibles por aplicación de un derecho común.

Ésta expectativa no es sólo generosa por esclarecer las facultades de los árbitros lo es también a favor de alivianar la yuxtaposición de fuentes normativas que pesan sobre un proceso de arbitraje, que se simplifican en la práctica pero que existen. Observemos a primera vista que el procedimiento se institucionaliza ante un Tribunal que cuenta con un Reglamento que a su vez deriva en un Código Procesal, y que éste Tribunal o las partes optan por un instrumento internacional específico a lo cual se agrega el derecho aplicable al fondo de la cuestión.

Consideremos, que la pluralidad de fuentes plantea graves problemas a la hora de concretar el régimen jurídico del arbitraje sobre todo del internacional; las dificultades de coexistencia de pluralidad de fuentes se ve agudizada por los desfasajes en que frecuentemente incurren los legisladores nacionales al tiempo de crear leyes nacionales en materia de arbitraje, al punto de quedar en proyectos pendientes que no adquieren vigencia.

Observemos que la reglamentación a través de leyes nacionales es trascendente a la hora de cubrir la ausencia de tratados internacionales o bien de interpretarlos y sobre todo, la posibilidad de clarificar a través de su sanción la posición de un Estado y de su doctrina legislativa frente a determinado instituto o procedimiento.

En nuestros días, el arbitraje interno e internacional requiere del soporte de una ley específica de orden nacional; la autonomía disciplinaria y la especificidad adquirida por el arbitraje, no se conforma

24 La jurisprudencia se ha expresado en éste sentido y cito como ejemplo "Administración Nacional de Usinas y Transporte Eléctrico del Uruguay c. Hidroeléctrica Piedra del Águila S.A. s. Acción meramente declarativa", fallo de la C.N.C y C, Sala II, de 26/08/03.

25 CAIVANO Roque (1998) "Medidas cautelares en el arbitraje". Jurisprudencia Argentina, IV, p. 47.

26 Al respecto véase fallo de la CNCom., sala E, 20/03/2013- Omni Security Services S.A. s. Queja: "La procedencia de la jurisdicción arbitral se encuentra sujeta a la voluntad de los interesados quienes, mediante una cláusula compromisoria, pueden renunciar a la jurisdicción de los tribunales ordinarios y someterse a la primera". 
con la contención otorgada por los Códigos Procesales.

La uniformidad no se logra exclusivamente por la existencia de un único instrumento en el caso, internacional; se avanza en ella si los ordenamientos nacionales se encuentran no necesariamente en identidad de condiciones, pero por lo menos en paridad. Estamos frente a una situación no sólo creadora de leyes sino también correctora de las existentes, con preciso establecimiento de pautas de valor.

\section{REFERENCIAS BIBLIOGRÁFICAS}

ALBACAR LÓPEZ José Luis (1981) “El derecho a la tutela jurisdiccional”. La Ley (2), p. 914 y sgtes.

ALBALADEJO Manuel (1990) "El arbitraje testamentario". Actualidad Civil Aranzadi, (6).

BOELE-WOELKI Katharina (2009) Unifying and Harmonizing Substantive Law and the Role of Conflict of Laws. Amsterdam: Hague Academy of International Law.

BROTONS Remiro (1980) Sentencias arbitrales extranjeras. Madrid: Editoras de Derecho Reunidas.

CAIVANO Roque (1998) "Medidas cautelares en el arbitraje". Jurisprudencia Argentina, IV, p. 47.

CAIVANO Roque (2013) "Independencia e imparcialidad de los árbitros y buena fe procesal". La Ley, Buenos Aires, noviembre 8, p. 6-7. CAMPS Carlos Enrique (2012) Tratado de las Medidas Cautelares. Buenos Aires: Abeledo-Perrot.

ESPUGLES MOTA Carlos (1997) "El juez y el árbitro en el Arbitraje Comercial Internacional". Cuadernos de Derecho Judicial (1), p. 13-57. FERNÁNDEZ ROZAS J., DE MIGUEL ASENSIO P. (2012) Derecho Internacional Privado. Madrid: Thomson Reuters.

FERNÁNDEZ-ARMESTO Juan (2005) "El arbitraje internacional en la nueva ley de arbitraje española”. Revista de Derecho Mercantil, (258), p. 1469-1532.

FRESNEDO de AGUIRRE Cecilia (2012) "El arbitraje internacional: presencia y evolución en el ámbito jurídico uruguayo”. En OYARZÁBAL Mario J. A. (coord.) Derecho Procesal Transnacional. Homenaje al Prof. Dr. Gualberto Lucas Sosa. Buenos Aires: Edición Ábaco.

GARCIMARTÍN ALFÉREZ Francisco J. (2012) Derecho Internacional Privado. Madrid: Thomson Reuters.

GÓMEZ JENE Miguel (2004) "El arbitraje internacional en la nueva ley de arbitraje”. Diario La Ley (5952), Madrid, febrero 11.

JUENGER F. K. (1998) Contratación internacional, comentarios a los principios sobre contratos comerciales internacionales del UNIDROIT. México: Universidad Nacional Autónoma de México.

LORCA NAVARRTE Antonio María (2007) "Problemas prácticos y teóricos que plantea la adopción de medidas cautelares en el modelo de 
Arbitraje internacional y toma de medidas cautelares. Liliana Etel Rapallini

arbitraje UNCITRAL/CNUDMI”. Diario La Ley (6634), Madrid, 22 de enero de 2007.

MARCHESINI Gualterio Martín (2006) "Las medidas cautelares en el proceso arbitral comercial”. La Ley, 2006-C, Buenos Aires, mayo 26.

MARTIN BRAÑAS Carlos (2012) "La declinatoria como instrumento adecuado para alegar en el proceso jurisdiccional el sometimiento de la cuestión litigiosa a arbitraje". Revista de Arbitraje Comercial y de Inversiones, 3(1), p. 160-171.

MERINO MERCHÁN José Francisco, CHILLÓN MEDINA José María (2006) Tratado de Derecho Arbitral. 3ra. ed. Madrid: Thomson - Civitas. OLIVENCIA RUIZ Manuel (2005) Arbitraje Mercantil - Ensayo sobre una justicia alternativa. Escritos Jurídicos. Sevilla: Fundación El Monte. OLIVENCIA RUIZ Manuel (2010) Derecho mercantil y proceso. Madrid: Estudios de la Real Academia de Jurisprudencia y Legislación.

PRIETO CASTRO Leonardo (1955) Problemas debatidos en el Primer Congreso Ibero-Americano de Derecho Procesal y en particular, el arbitraje. Lecciones pronunciadas en la Universidad de Deusto los días 5, 6, y 7 de Diciembre de 1955. Bilbao: ARTE.

ROGEL VIDE Carlos (2006) "El convenio arbitral y el arbitraje testamentario". Revista General de Legislación y Jurisprudencia, (3).

SAGRARIO Ramiro (2013) "El acuerdo de arbitraje en el Proyecto de Código": La Ley, Buenos Aires, 29 de agosto de 2013.

SANTOS BELANDRO Rubén (2004) "Hasta qué punto puede diluirse la formalidad del Acuerdo de Arbitraje Internacional en América Latina”. Revista Mexicana de Derecho Internacional Privado y Comparado, (15), p. 81-91.

SANTOS BELANDRO Rubén (2008) Derecho comercial Internacional. Montevideo: Asociación de Escribanos del Uruguay.

VALLET de GOYTISOLO Juan (2010) La función de juzgar y sus aportaciones al arte y la ciencia del Derecho. Madrid: Real Academia de Jurisprudencia y Legislación. Madrid.

VERDERA y TULLES Evelio (2005) La ley 60/2003, de arbitraje entre la tradición y la innovación. Madrid: Real Academia de Jurisprudencia y Legislación. 